\title{
Tele-monitoring of ventilator-dependent patients: a European Respiratory Society Statement
}

\author{
Nicolino Ambrosino ${ }^{1}$, Michele Vitacca², Michael Dreher ${ }^{3}$, Valentina Isetta ${ }^{4,5}$, \\ Josep M. Montserrat ${ }^{6,5}$, Thomy Tonia ${ }^{7}$, Giuseppe Turchetti ${ }^{8}$, Joao Carlos Winck ${ }^{9}$, \\ Felip Burgos ${ }^{10}$, Michael Kampelmacher ${ }^{11}$ and Guido Vagheggini ${ }^{1}$ on behalf of \\ the ERS Tele-Monitoring of Ventilator-Dependent Patients Task Force
}

\begin{abstract}
Affiliations: ${ }^{1}$ Auxilium Vitae, Volterra, Italy. ${ }^{2}$ Fondazione Salvatore Maugeri, Centro Medico di Lumezzane, Italy. ${ }^{3}$ Dept of Cardiology, Pneumology, Angiology and Intensive Care Medicine, University Hospital Aachen, Aachen,

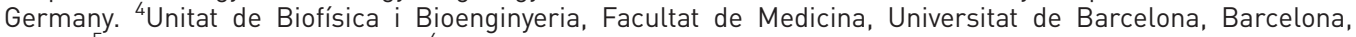
Spain. ${ }^{5}$ CIBERES, Madrid, Spain. ${ }^{6}$ Sleep Unit, Respiratory Dept, Hospital Clínic, Universidad de Barcelona, IDIBAPS, Barcelona. ${ }^{7}$ Institute of Social and Preventive Medicine University of Bern, Switzerland. ${ }^{8}$ Institute of Management, Scuola Superiore Sant'Anna, Pisa, Italy. ${ }^{9}$ Faculdade de Medicina, Universidade de Porto, Portugal. ${ }^{10}$ Dept of Pulmonary Medicine (ICR), Hospital Clínic, Universidad de Barcelona (IDIBAPS) CIBERES, Spain. ${ }^{11}$ Home Ventilation Service, University Medical Center Utrecht, The Netherlands.
\end{abstract}

Correspondence: Nicolino Ambrosino, Clinical Department, Auxilium Vitae, Borgo S Lazzaro 56048, Volterra, Italy. E-mail: nico.ambrosinolagmail.com

ABSTRACT The estimated prevalence of ventilator-dependent individuals in Europe is 6.6 per 100000 people. The increasing number and costs of these complex patients make present health organisations largely insufficient to face their needs. As a consequence, their burden lays mostly over families. The need to reduce healthcare costs and to increase safety has prompted the development of tele-monitoring for home ventilatory assistance.

A European Respiratory Society Task Force produced a literature research based statement on commonly accepted clinical criteria for indications, follow-up, equipment, facilities, legal and economic issues of telemonitoring of these patients.

Many remote health monitoring systems are available, ensuring safety, feasibility, effectiveness, sustainability and flexibility to face different patients' needs. The legal problems associated with tele-monitoring are still controversial. National and European Union (EU) governments should develop guidelines and ethical, legal, regulatory, technical, administrative standards for remote medicine. The economic advantages, if any, of this new approach must be compared to a "gold standard" of home care that is very variable among different European countries and within each European country.

Much more research is needed before considering tele-monitoring a real improvement in the management of these patients.

@ERSpublications

More research is needed to consider tele-monitoring an improvement in routine care of ventilator dependent patients http://ow.ly/16gM300hEhx

Earn CME accreditation by answering questions about this article. You will find these at erj.ersjournals.com/journal/cme Received: Oct 192015 | Accepted after revision: March 102016 | First published online: July 072016

This task force document was endorsed by the ERS Science Council and ERS Executive Committee in April 2016

Conflict of interest: Disclosures can be found alongside the online version of this article at erj.ersjournals.com

Copyright OERS 2016 


\section{Introduction}

The reported, although probably underestimated, prevalence of patients with chronic respiratory failure (CRF) requiring home mechanical ventilation (HMV) in Europe is 6.6 per 100000 people [1]. There are challenges when providing HMV, including patients and caregiver training, adequacy of respiratory care, reimbursement policy, and need of patient/family cooperation [2]. Furthermore, factors such as patients' chronic diseases and their exacerbations, need of technology and lack of professional supervision make the management of ventilator dependent individuals (VDI) by family and non-professional caregivers a difficult task. Supervision by external companies has many limitations, such as lack of standardisation, lack of regular feedback to the prescribing centres [3], costs and logistical problems. The need to reduce healthcare costs and to improve safety has prompted the development of tele-monitoring for VDIs.

Information and communication technologies (ICT) applied to health and healthcare systems have been considered able to increase their efficiency, improve quality of life and unlock innovation in health markets. However, the EU considers this promise as still largely unfulfilled [4]. There is some confusion about the terms used to define tele-health, as well as tele-medicine versus tele-monitoring. Home mechanical ventilators are sometimes equipped with remote monitoring tools in order to improve supervision on the delivered treatment and adapt settings to the patient's need and comfort accordingly [5]. The economic issues of home tele-monitoring are crucial for its rapid transfer to healthcare systems both in terms of cost/benefit ratio and in term of reimbursing rules [6]. An assessment of the costs associated to such an innovative application should be investigated in detail, together with regulatory (legal, insurance and reimbursement) issues. Other relevant issues may include [7]: indications, modalities of follow-up, team expertise and composition, technologies, outcome, adherence and compliance measures, tele-rehabilitation programmes. The aim of this European Respiratory Society (ERS) task force was to provide a statement describing commonly accepted indications, follow-up schedules, equipment and facilities, legal issues (if any). This may be useful to: 1) Promote common standards of clinical criteria, data transmission, management pathways, equipment, facilities, and regulations of tele-monitoring systems in countries where these tools are already in use. 2) Describe models for countries developing new HMV systems of care. 3) Design clinical studies in the field for HMV. Definitions regarding terminology referred to in this report are given in box 1 .

\section{Methods}

Members of the task force searched EMBASE, CINALH, PubMed, PsychINFO and Scopus data bases using the following keywords: ventilator-dependent, tele-monitoring, home mechanical ventilation, sleep disorders, respiratory tele-medicine, tele-monitoring AND end of life. Papers published between 2003 and 2015 in English language were considered. Members assessed the identified studies for appropriateness. For questions where there was a lacking in studies on VDIs, studies on non-ventilator dependent patients were examined. Among 2975 papers, 150 were considered as appropriate for analysis. The document was discussed among task force members by emailing correspondence, and in two, face-to-face meetings at the ERS International Congress in 2014 and in 2015.

Tele-medicine has three dimensions: functionality, applications and technology. Applications may refer to specialty, disease, site, or treatment [8].

\section{Clinical scenarios}

\section{Neuromuscular diseases}

Tele-monitoring has been used in neuromuscular diseases (NMD) management. A prospective, single-blind controlled trial [9] of home noninvasive ventilation (NIV) in amyotrophic lateral sclerosis (ALS), showed that compliance to NIV with or without tele-monitoring was similar, whereas NIV initial setting was successfully managed by tele-monitoring. This study showed also that tele-monitoring might offer potential favourable effects on costs, survival and functional status. A study [10] showed the easy use of a tele-monitoring device, whereas another study [6] showed that tele-monitoring was cost-effective as compared to office-based follow-up control visits with a $€ 700$ patient year cost saving. Tele-monitoring has been used also in other NMD. In one study, by ZAMARRÓN et al. [11], only three patients were rated by the authors as easy to use a platform consisting of video-conferencing and tele-monitoring of cardio-respiratory variables. Another prospective observational study, by GARUTI et al. [12], showed that the combination of tele-monitoring and chest physiotherapy performed at home was feasible and resulted in reduction in hospital admissions.

\section{Chronic obstructive pulmonary disease}

The usefulness of long-term NIV in hypercapnic CRF due to chronic obstructive pulmonary disease (COPD) is still discussed. The addition of long-term NIV to standard treatment improves survival in these patients when it is aimed to significantly reduce arterial carbon dioxide tension [13]. Daily variations in respiratory rate and percentage of respiratory cycles triggered by the patient might be able to predict the risk for acute COPD exacerbations [14] and tele-monitoring is feasible to modify therapy in these patients [15]. 
BOX 1 Terminology definitions

Tele-medicine

Tele-communications

Telematics

Tele-consultation

Tele-monitoring

Decision support systems

Remote diagnosis

Tele-therapy

Tele-evaluation

Telecare

Tele-rehabilitation

Tele-coaching

Tele-conference, audio

Emergency calls

Tele-hospice
Distribution of health services in conditions where distance is a critical factor, by health care providers that use information and communication technologies to exchange information useful for diagnosis where doctor is able to perform diagnosis at distance.

Use of cable connections, the radio, optical means or other electromagnetic channels to transmit or receive signals such as voice, data or video communications.

Use of telecommunications to permit computers to transfer programmes and data.

Second opinion on demand between patient/family and staff or among health operators; opinions, advice provided at distance between two or more parties separated geographically.

Digital/broadband/satellite/wireless or Bluetooth transmission of physiologic and other non-invasive data (i.e. biological storage data transfer).

According to a sentinel value, an alert starts for health personnel who call patient.

Identifying a disease by the assessment of the data transmitted to the receiving party through instrumentation monitoring a patient away.

Direct prescription.

On-demand data transfer to use as biological outcome measures.

Network of health and social services in a specific area; in case of emergency, patient calls medical personnel, emergency call service or members of family.

Allowed to receive homecare and guidance on the process of rehabilitation through connections for point-to-point video conferencing between a central control unit and a patient at home.

Direct reinforcement or recorded messages/communications to improve adherence.

Electronic two-way voice communication between two or more people located in different places, which make use of transmission systems voice, video and/or data.

A service that gives the ability to initiate a call for help to an operation centre, usually active $24 \mathrm{~h}$ a day throughout the year.

The use of tele-medicine technologies to provide palliative services to patients with severe chronic disease or living with and dying from advanced illness.

Starting NIV outside the hospital with the help of tele-monitoring might be an option in these patients since it has been shown that home based NIV initiation is not inferior to hospital adaption in restrictive thoracic diseases, NMD and obesity-hypoventilation patients being cost saving for the healthcare systems [16, 17]. Nevertheless clear conclusions based on randomised controlled trials (RCT) of tele-monitoring in these patients are lacking.

Weaning

We identified only one case report about weaning from mechanical ventilation of a patient at home, with the help of telephone assistance [18]. The patient was able to increase the time of spontaneous breathing.

\section{Equipment and technology}

The components of the technological dimensions can be grouped into four variables: synchronicity, network design/configuration, connectivity and inter-operability [19]. 


\section{Synchronicity}

Synchronicity is used here to incorporate both timing and technology. With regard to timing, tele-monitoring may be "synchronous", i.e. in real time, interacting simultaneously with participants in different places. These systems provide constant analytical and decision making support. Monitoring centres are usually led by physicians, staffed with specialised nurses, and have full, therapeutic authority 24/7. Data transfer is synchronous, meaning a real time processing of patient data by means of automated algorithms to interpret them. Care providers can recognise important changes in essential measurements, but delays can occur if the systems are only active during office hours. Other systems are "asynchronous" (store-and-forward); the participants do not interact in real time. There is no full tele-medical system, and the provider cannot respond immediately to patient needs. This, second generation, system has a non-immediate analytical or decision making structure.

\section{Network design/configuration}

Network design/configuration includes three modalities: virtual private networks, the open internet, and social networks, in which information is posted and shared. These three modalities substantially vary in terms of security and ability to protect confidential information. Patient empowerment and digital health literacy are essential for successful e-health deployment. Although the EU Commission [4] supports activities aiming at increasing digital health literacy, a significant barrier lies in the lack of awareness of e-Health opportunities and challenges for users (citizens, patients, health and social care professionals) [4].

\section{Connectivity}

Connectivity can be wired and wireless, both of which providing different levels of band-width, the attendant speed and resolution or service quality.

\section{Inter-operability}

Health Level Seven (HL7) International is a not-for-profit, American National Standards Institute (ANSI)-accredited standards developing organisation, dedicated to providing a comprehensive framework and related standards for the exchange, integration, sharing, and retrieval of electronic health information that supports clinical practice and the management, delivery and evaluation of health services. The Clinical Document Architecture, Release Two (CDA R2) standard by HL7 [20] is a product of HL7 International that is dedicated to the production of standards in healthcare in order to facilitate inter-operability. CDA defines the structure of a clinical document and uses the extensible mark-up language (XML) to label different categories of information, making the inter-operability among different healthcare providers and settings possible, executing exploitation services, facilitating the implementation of systematic control processes [21].

Table 1 summarises the literature on electronic devices, type of transferred signals and rationale for their use. Many remote health monitoring systems are available. The appropriate technology may result in safety, feasibility, effectiveness, sustainability and flexibility to face different patients' conditions.

\section{Follow-up}

There is poor exchange of information and feedback among the centres prescribing HMV and the external companies performing the ventilator servicing, with the frequency of communication ranging from 3-12 months $[3,15]$. Tele-monitoring may play a major role in improving HMV quality control, by remotely monitoring ventilation variables and facilitating exchange of information on quality control among partners involved in HMV. Some programmes used weekly [42] or 3-month [43] phone calls as "store and-forward necessity". VITACCA et al. [14, 18] proposed an interactive online system: continuous on-call service was available $24 / 7$ and arterial oxygen saturation measured by pulse oximetry $\left(\mathrm{SpO}_{2}\right)$ was accessible for check-point analysis $[14,18]$.

Timing of evaluation of compliance to continuous positive airway pressure (CPAP) devices and feed-back has been defined in the setting of obstructive sleep apnoea (OSA) management [44]; downloaded information every week day morning (except holidays) and contacts to the patient, if any, of the following were present: mask leak $>40 \mathrm{~L} \cdot \mathrm{min}^{-1}$ or $>30 \%$ of the night, $<4 \mathrm{~h}$ use for two consecutive nights, machine measured apnoea-hypopnoea index $(\mathrm{AHI})>10$ events. $\mathrm{h}^{-1}$, and 90 th percentile of pressure $>16 \mathrm{cmH}_{2} \mathrm{O}$. The research coordinator called the patient and inquired about symptoms/side effects [44].

In a pilot study published as an abstract [45], of titration and surveillance of HMV initiation, authors used a ventilator connected with oximetry and Global System for Mobile Communications (GSM) modules and Encore Anywhere software (Koninklijke Philips N.V., Amsterdam, the Netherlands). Compliance data were downloaded on the 4th day and the 2nd month, while nocturnal oximetry (under HMV) was performed on the 7 th day and the 1st month. If efficacy of ventilation criteria were not fulfilled, remote titration of ventilator settings were based on compliance/oximetry downloads (COD). At COD assessments phone calls were made 
BERTINI [22] Digital multi-parametric recorder

VITACca [23] Phone, pulse oximeter sensor, oximeter with solid memory card plus a modem system and home telephone line

\section{Ritchie [24] An interactive voice response and personal phone \\ MiYASAKa[25] \\ A tablet computer with webcam}

Vontetsianos [26] Video conference camera

Holland [27] Commercially available webcam devices

SмIтн [28] Video device

\section{Paget [29]}

TAKAHASHI [30]

Segrelles [31] Spirometer, a pulse oximeter and heart rate monitor (Spirotel; MIR Waukesha, WI, USA), blood pressure monitor (model UA-767 BT; A\&D San Jose, CA USA), modem (Tele-Modem; Aerotel Medical Systems, Holon, Israel), and telephone lines

URE [32]

PInNock [33]

Touch screen computer

Touch screen, algorithms, telephone, and video link

ZАMITH [34]

DocQAHome device (Docobo, Leatherhead, UK), oximetry (BCI 3303; Smiths Medical PM, Inc. Waukesha WI, USAI plus ECG

Trappenburg [35] Portable device Health Buddy system
Tidal volume, respiratory frequency, minute ventilation, arterial oxygen saturation, heart rate, inspiratory positive airway pressure, expiratory positive airway pressure

Voice, pulse oximetry data, pulse oximetry trend

Recorded voice

Video images

Voice

Skin colour vital signs

Blood pressure cuff, glucometer, pulse oximeter,

Scales, blood pressure cuff, glucometer, pulse oximeter, and peak flow data

Blood pressure cuff, glucometer, pulse oximeter, heart rate and peak flow data

\section{Questionnaire answers}

Questionnaire answers, video images and voice

Peak expiratory flow rate, oximetry,

ECG and messages

Oximetry, ECG; clinical questionnaires; messages
Once a week nocturnal monitoring and a telephone counselling, when needed, available $24 / 7$ with medical doctors in charge

Calls contacts, home support helpline to identify patient/equipment problems and strategies to minimise risk for patients, healthcare teams and manufacturers; monitoring

\section{E-coach}

Video conferencing

Rehabilitation programme prescription and adherence monitoring

Caregiver's use of the patient equipment, equipment demonstrations, visual illustrations,

audio-recorded educational directions to facilitate patient care

Daily recording of signals

Real-time video conferencing capability tele-monitoring

Tele-monitoring

To record a validated daily symptom score comprising questions

Tele-monitoring: the participant recorded and transmitted a daily questionnaire about symptoms and use of treatment and monitored oxygen saturation

Monitoring signal and compliance, symptoms, medication, sleep quality, smoking, impact on exertion, and weight

To transfer patient-clinician data by Internet to doctors; functional monitoring and prescription 
TABLE 1 Continued

Author [ref.]

Electronic device

Signals

Rationale for use

ALoNso [36]

Sensors connected through a body area network with a platform configured to display the data and

transfer it to the server using general packet radio service

Pedone [37] SweetAge monitoring system, Bluetooth transmitter, commercial pulse-oximeter, Bluetooth transmitter coupled with the wristband, commercial cellular telephone coupled with the wristband via Bluetooth connection, and telephone equipped with software

ANTONIADES [38] Laptop computer touch plate stethoscope pneumotachograph, thermometer, and questionnaire programme

Pinto [9],

Modem device with internal memory and integrated

De Almeida [10] transmission, oximeter (Pulsox-3iA; Konica Minolta Sensing, Osaka, Japan) with SR-5C finger clip (Konica Minolta Sensing) and helpline number

HAZENBerg [17] Telephone, transcutaneous monitor, laptop, and software programme.

ZamarRon [11] Commercially available telemedicine system, set top box connected to the television as a user interface, simple menu on television screen.

FraYsse [39]

CPAP Secure Digital card

ISHIDA [40]

Wearable respiration monitoring system. (piezoelectric sensor, a low-power 8-bit single chip

microcontroller, EEPROM and a $2.4 \mathrm{GHz}$ low-power transmitting mobile phone)

Nikander [41] Telehealth enabled nebulizer system (Prodose Adaptive Aerosol Delivery System; Philips Respironics, Chichester, UK

BoReL [15]

Noninvasive ventilation software
Vital signs

Heart rate, physical activity, near-body

temperature, and galvanic skin response

Blood pressure, pulse oximeter, electrocardiogram temperature, and information

Tidal volume, respiratory frequency, minute ventilation, arterial oxygen saturation, heart rate, inspiratory positive airway pressure and expiratory positive airway pressure

Ventilator information (e.g. volume, frequency, pressure levels, hours ventilator), carbon dioxide and oxygen saturation

Oximetry, blood pressure and ECG alarms

Hours of use, CPAP level and leaks

Sequentially stores the movement signa
EXACT-Pro questionnaire every day plus continuous monitoring of respiratory rate, percentage of respiratory cycles triggered by the patient and noninvasive ventilation daily use
Vital signs are collected and may be transmitted to the data monitor centre

Functional and physical activity monitoring allowing for reception of data transmitted by the wristband and acted as a gateway to send the data to the monitoring system

Data uploaded daily to a central server via internet connection through the patient's telephone line. Scales for overall health, dyspnoea, sputum colou and volume, symptoms of respiratory tract infection and changes in medication usage

Ventilator Goodknight 425ST bi-level (Puritan Bennett, Gosport, UK) device monitoring

Ventilator device monitoring use

Remote monitoring of biological signals, videoconferencing,

Data transmitting box every week for 2 months

Detection of sleep apnoea syndrome, whether the patient has breathed during that time

To delivery repeat medication in cystic fibrosis

To assess daily variations in three parameters to predict the risk of exacerbation in patients with chronic obstructive pulmonary disease treated by home noninvasive ventilation

CPAP: continuous positive airway pressure; EEPROM: electrically erasable programmable read-only memory; EXACT-PRO: the exacerbations of chronic pulmonary disease tool patient-reported outcome. 
by the homecare provider in order to check performance of the study protocol [45]. BERTINI et al. [22], were able to avoid emergency visits in $62.5 \%$ of cases with once a week and on-demand nocturnal monitoring, using a Digital multiparametric recorder that included ventilator parameters and $\mathrm{SpO}_{2}$ coupled with a telephone counselling.

\section{Equipment and technology for follow-up}

There are different technologies and timings for data collection, ranging from digital videophone systems, alone [25] or coupled with other systems [26] to weekly transmission of ventilator data through modems, weekly phone interviews by nurses coupled with oximetry download through modems [34, 46-48], daily oximetry readings [46-48], customised or commercial multifunctional devices [34, 35, 49]. For severe COPD patients with CRF tele-spirometry may help in the monitoring of lung function and complement the information in the VDIs [34]. In patients with CRF (63\% of whom under HMV) ZAMITH et al. [34] collected peak expiratory flow rate data on a weekly basis coupled with symptom questionnaires filled daily. More recent touch screen tele-monitoring equipment with integrated questionnaires was used with the same frequency [45]. Other authors used stand-alone spirometers [31, 50] with modem transmission three times a week in COPD patients under long-term oxygen therapy (LTOT). Pedone et al. [37] used commercial cellular phones coupled with sensors allowing for five measurements of each parameter over 3 h. Maiolo et al. [42] monitored nocturnal $\mathrm{SpO}_{2}$ twice a week. Different devices can be hooked-up to the ventilator-monitoring system in order to provide a more comprehensive care. Which equipment, technology and periodicity are best in the different clinical scenarios remains to be defined. Table 2 shows a summary of the literature in the field.

\section{Legal issues}

The legal problems associated with tele-medicine are still controversial. Despite many processes of tele-consultation are unique, the legal principles applying to conventional, face-to-face, doctor-patient relationships may be equally as valid in the context of the practice of medicine at a distance [51, 52]. In tele-medicine, three roles can be held legally liable for the delivered performance [52]:

1) The person who transmits the data. Any application of tele-medicine is considered a medical act. The relationship between the person using the service (especially when he/she is the patient) and other stakeholders, must be governed by "informed consent". This preliminary action allows the patient to be adequately informed about the characteristics of the service, the potential risks, the precautions to reduce them and to ensure the confidentiality of the information [51].

2) The person who receives data. The person who conducts the remote health service: he/she is the medical user of the service and the medical consultant [51].

3) The service provider(s). The quality and confidentiality of the transmitted and received data must be ensured by service providers [51].

The use of tele-monitoring carries several risks [52-54]: tele-consultation may fail to reach standard of care; equipment or system may fail; electronic data can be manipulated; the electronic record may be subject to abuse; the network may suffer from poor data protection (poor confidentiality, authenticity, data report, procedure certification, security and privacy); the network may show difficulty to ascertain responsibilities and potential obligations of health professionals.

Important system precautions need to be used by e-Health users $[55,56]$.

\section{Data security and confidentiality}

Suppliers and users must ensure the confidentiality, the authenticity of the data and their report, the authorised certification of procedures with digital signature, the protection of confidentiality, the security and privacy of the assisted persons, the storage and transfer of sensitive data in real time between one unit and the other without manipulation.

\section{Responsibilities and potential obligations of health professionals}

Three key aspects need to be specified: 1) the responsibility of the physician (tele-consultant) and the patient at distance (tele-consulted), 2) the relationship and co-responsibility between specialist consultant and the requesting physician, and 3) the responsibility and the relationship among the applicant, consultant and service supplier or suppliers.

\section{Interoperability}

Mutual exchange of ICT-enabled solutions and of data are necessary for better coordination and integration across the entire chain of healthcare delivery to offer personalised solutions. Use of European and international standards to ensure the interoperability of ICT solutions to offer appropriate services. 
TABLE 2 Time and modality of follow-up schedules

\begin{tabular}{|c|c|c|c|}
\hline Author [ref.] & Population & Time to tele-assistance initiation & Time of TM use \\
\hline MIYASAKA [25] & $\begin{array}{l}\text { Paediatric patients for home } \\
\text { ventilatory care } n=7\end{array}$ & Implementation of a videophone system & NA \\
\hline Pinto [9] & ALS $n=40$, all ventilated & $\begin{array}{l}\text { Controls: admission, } 2-3 \text { weeks later, } \\
\text { every } 3 \text { month thereafter } \\
\text { Intervention: every week by modem; } \\
\text { every } 3 \text { month in-office }\end{array}$ & 3 years \\
\hline De Almeida [10] & ALS & Not mentioned & NA \\
\hline Vitacca [46] & $\begin{array}{l}\text { ALS } n=73 \text { (NIV } n=18 \text { and invasive } \\
\text { ventilation } n=18 \text { ) }\end{array}$ & $\begin{array}{l}\text { Median time from diagnosis to TM } 440 \text { days } \\
\text { Phone calls per patient per month } 4.8 \pm 2.5 \\
\text { Time per month of calls } 3-256 \text { min } \\
\text { Calls weekly scheduled or requested } \\
\text { by patient/career (unscheduled) }\end{array}$ & 4 years \\
\hline Vitacca [47] & $\begin{array}{l}\text { ALS } n=40 \text { (NIV } n=19 \text { and invasive } \\
\text { ventilation } n=12 \text { ) }\end{array}$ & $\begin{array}{l}8-6 \text { months }(1-12 \text { months }) / \geqslant 5 \text { calls } \\
\text { per patient per month } \\
\text { Total calls: } 2224 \\
\text { (1907 scheduled, } 317 \text { unscheduled) }\end{array}$ & $1-12$ months \\
\hline ZАMITH [34] & $\begin{array}{l}\text { Asthma } n=21 \text { plus CRF } n=51 \\
\text { (LTOT } n=41 \text { and NIV } n=32 \text { ) }\end{array}$ & Not mentioned & 9 months \\
\hline BERTINI [22] & $\begin{array}{l}\text { HMV } n=16 \text { (invasive } M V n=5, N I V n=11 \\
\text { COPD } n=3, \text { RTD } n=4, N M D n=8 \\
\text { Ondine Syndrome }{ }^{\#} n=1 \text { ) }\end{array}$ & $\begin{array}{l}\text { The data analysed routinely every week } \\
\text { or in real time after a phone call by the } \\
\text { patient or care givers to the doctor in charge }\end{array}$ & 2 years \\
\hline De Toledo [49] & COPD $n=157$ & On demand & 1 year \\
\hline VonteTsianos [26] & $\begin{array}{l}\text { COPD } n=18 \text { plus at least four hospitalisations in the } \\
\text { previous } 2 \text { years }\end{array}$ & Once a month via nurse & 9 months \\
\hline TRAPPENBURG [35] & COPD (study $n=59$, controls $n=56$ ) & Daily symptom surveillance & 6 months \\
\hline Segrelles [31] & $\begin{array}{l}\text { Home telehealth } n=30 \text {, controls } n=30 \text {; } \\
\text { FEV } 1<50 \% \text {, age } \geqslant 50 \text { years, LTOT, non-smokers, with } \\
\text { at least one hospitalisation for respiratory illness } \\
\text { in the previous year }\end{array}$ & $\begin{array}{l}\text { Monday-Sunday; From Monday through to Friday the } \\
\text { data is monitored and assessed by the Clinical } \\
\text { Monitoring Center from 09:00 h to } 17: 00 \mathrm{~h} \text { and during } \\
\text { weekends the data is directly analysed } \\
\text { by pulmonologist }\end{array}$ & 7 months \\
\hline JódAR-SÁNCHEZ [50] & $\begin{array}{l}\text { Telehealth } \mathrm{n}=24 \text { and control group } \mathrm{n}=21 \text { on usual care; } \\
\text { under LTOT and with at least one hospitalisation for } \\
\text { respiratory illness in the previous year }\end{array}$ & $\begin{array}{l}\text { Vital signs on weekdays and } \\
\text { spirometry ( } 2 \text { days per week) }\end{array}$ & 4 months \\
\hline MAIOLO [42] & COPD patients on LTOT $n=2 f 0$ and RTD $n=3$ & Twice a week & 12 months \\
\hline MoREIRA [45] & $\begin{array}{l}\text { Patients } \mathrm{n}=35 \text { (OSA } 40.0 \% \text {, COPD } 22.8 \% \text {, NMD } 11.4 \% \text {, TB } \\
\text { sequelae } 2.9 \% \text {, kyphoscoliosis } 2.9 \% \text { and } 20.0 \% \text { other } \\
\text { CRF causes) }\end{array}$ & $\begin{array}{l}\text { Compliance downloads on fourth day and } \\
\text { second month, nocturnal oximetry on } \\
\text { seventh day and first month }\end{array}$ & 3 months \\
\hline Pinnock [33] & $\begin{array}{l}\text { Patients randomised to tele-monitoring } n=128 \text {, patients } \\
\text { randomised to usual care } n=128\end{array}$ & $\begin{array}{l}\text { Daily questionnaire about symptoms } \\
\text { and oxygen saturation }\end{array}$ & 12 months \\
\hline Pedone [37] & $\begin{array}{l}\text { COPD } n=50 \text { (GOLD II and III) patients in the } \\
\text { tele-monitoring group and controls } n=49\end{array}$ & $\begin{array}{l}\text { System set up to perform five measurement } \\
\text { of each parameter every } 3 \mathrm{~h}\end{array}$ & 9 months \\
\hline Vitacca [23] & $\begin{array}{l}\text { CRF patients needing LTOT or HMV plus at least one } \\
\text { hospitalisation for respiratory illness in the previous } \\
\text { year, COPD } 56 \% \text {, RTD } 15 \% \text {, NMD } 10 \% \text {, ALS } 9 \% \text {, other } \\
10 \% \text {; of which } 46 \% \text { on NIV, } 21.4 \% \text { on IMV and } 63 \% \\
\text { onLTOT }\end{array}$ & $\begin{array}{l}\text { Continuous } 24 \mathrm{~h} \text { on-call service } \\
\text { (interactive online system) }\end{array}$ & 1 year \\
\hline BoREL [15] & COPD on home NIV & $\begin{array}{l}\text { EXACT-Pro questionnaire every day plus continuous } \\
\text { monitoring of respiratory rate percentage of } \\
\text { respiratory cycles triggered } \\
\text { by the patient and NIV daily use }\end{array}$ & 6 months \\
\hline
\end{tabular}

NA: not available; ALS: amyotrophic lateral sclerosis; NIV: noninvasive ventilation; TM: tele-monitoring; CRF: chronic respiratory failure; LTOT: long-term oxygen therapy; HMV: home mechanical ventilation; MV: mechanical ventilation; COPD: chronic obstructive pulmonary disease; RTD: respiratory tract disease; NMD: neuromuscular disorders; FEV1: forced expiratory volume in $1 \mathrm{~s}$; EXACT-PRO: the exacerbations of chronic pulmonary disease tool patient-reported outcome. \#: Also known as congenital central hypoventilation syndrome (CCHS). 
With the increasing diffusion of this technology, case law will be updated and give answers to issues unresolved now. National and EU governments should promote common, ethical, legal, regulatory, technical, and administrative standards for remote medicine to assist VDIs and caregivers in providing safe and effective services [57].

\section{Economic considerations}

The proportion of the elderly (aged $>65$ years and $<80$ years) and older (aged $\geqslant 80$ years) EU population is expected to rise from $17.4 \%$ in 2010 to $30.0 \%$ in 2060 and from $4.7 \%$ in 2010 to $12.1 \%$ in 2060, respectively. Patients often suffer from acute exacerbations of their chronic diseases resulting in frequent hospitalisations in intensive care units (ICUs) or emergency room admissions, as well as general practitioner (GP) visits. As a result, the EU average health expenditure rose from $5.9 \%$ in 1990 to $7.2 \%$ of gross domestic product (GDP) in 2010, and the projections show that it may further grow to $8.5 \%$ GDP in 2060, due to the ageing population and other socio-economic and cultural factors. In addition, the long-term care expenditure projection would on average almost double over this period. The impact of these changes is already being perceived and is worsened by increased pressure on public budgets, progressive decline in the number of health personnel, and growing demands and expectations from citizens for higher quality services and social care [58-62].

\section{Challenges and opportunities}

Tele-monitoring can be considered as both a challenge and an opportunity for health services [63]. Particular attention is given to dimensions such as safety, usability, and quality of patients' knowledge of their disease as the key factor of an effective self-management [64]. As a consequence, HMV requires a big amount of human and financial resources [67]. Some studies have evaluated and compared the costs associated to home and institutional or hospital setting alternative solutions. An early paper from FIELDS et al. [66] on the cost-effectiveness of homecare technology for respiratory technology-dependent children, reports a mean annual homecare cost $>\$ 100000$ USA for ventilator-dependent children, and $>\$ 60000$ for oxygen-dependent tracheotomised patients, respectively. This corresponds to $\sim \$ 79000$ and $\$ 83000$ per patient saving, respectively, compared to alternative institutional cares. Another study [67] on ventilator dependent children showed that health costs were $70 \%$ less than hospitalisation-related costs, while the average costs for homecare were $87 \%$ less than a hospital setting care. In the UK, NOYES et al. [68] compared the costs of service for ventilator dependent children and young people at home and in hospital settings. They found that living at home for children not needing employed carers was always cheaper than living in the hospital. However, for children needing $24 \mathrm{~h}$ care by qualified nurses, the homecare package was $\sim 1.5$ time more expensive than for children treated in the hospital setting. Also a recent literature review [61] outlines that HMV is a more cost-effective therapy compared to in-patient care in ICUs reporting a cost reduction ranging from $62 \%$ to $74 \%$ in general. Furthermore, invasive HMV has a higher cost compared to home NIV, principally due to the care equipment and partially due to the need for 24-h care by highly qualified personnel. Available comparisons of institutional and at home solutions in VDI may underestimate the importance of comparing at home alternatives such as: 1) tele-monitoring versus formal caregiver monitoring in VDI's homecare, to highlight the savings associated to tele-monitoring when compared to high intensity labour home activities; and 2) quality-of-life comparison in patients using home and hospital care solutions.

Table 3 shows the few studies reporting the cost-effectiveness of remote monitoring in VDIs. For example, the study by VITACCA et al. [23] concluded that tele-monitoring was cost-effective in case of severe and frail patients when LTOT and/or either NIV ventilator or invasive mechanical ventilation are needed, considering activation and healthcare service provision costs. Constant costs were mainly based on the number of calls, and savings in healthcare services costs were mainly due to the prevented hospitalisations. Per patient costs were $\sim 33 \%$ less than for usual outpatient follow-up, whereas per COPD patients tele-monitoring costs were about 50\% less than for usual outpatient follow-up. Despite these preliminary studies have shown an advantage in applying tele-health systems, recent research casts some doubts that these systems are more effective and less expensive than usual care [70-72].

To evaluate the real cost/effectiveness of new methods such as remote monitoring in this population it is important to understand what "standard therapy" and "usual therapy" mean in the papers published until now. It is clear that the superiority (if any) of this new method of care must be compared to a "gold standard" of homecare that is very variable among the European countries and within each European country [57].

Alternatively, tele-monitoring may represent an opportunity for health services. Despite the economic crisis, the potential e-health market is strong. The global tele-medicine market has grown from $\$ 9.8$ billion in 2010 to $\$ 11.6$ billion in 2011, and is expected to continue to grow to $\$ 27.3$ billion in 2016, representing a compound $18.6 \%$ annual growth rate [4]. The health market enabled by digital technologies (mobile 
TABLE 3 The economic impact of ventilator dependent individuals tele-monitoring

\section{Author [ref.]}

\section{Lopes [6]}

VITACCA [69]

\section{Vitacca [23]}

Study design

NIV follow-up by tele-monitoring plus regular office visits at 3-month intervals versus NIV follow-up by regular office visits at hospital centre

Economic evaluation

Economic impact of home tele-monitoring

\section{Study population}

2003-2006 prospective quasi-randomised and singleblind trial with ALS patients aged $18-75$ years, 40 patients 20 tele-monitoring and 20 controls)

Outcome measurements Intention-to-treat analysis considering three different type of costs, costs estimated by DRG

Type of costs

Hospital direct costs: outpatients' office and emergency visits, hospital admissions, transportation, price per hour consultant specialist, daily rental of ventilators and associated settings, daily maintenance of monitoring equipment; NHS directs costs: total costs for daily care for patient Indirect costs: non-medical costs considering loss of earnings due to caregivers absenteeism

Hospital costs mean total

costs per patient higher in the intervention group $€ 15791 \pm 14361$ versus $€ 5734 \pm 4276$ ( $p=0.008$ ), mean annual costs per patient not statistical different (control $€ 8882.8 \pm 2718.5$ intervention group $€ 9508 \pm 1325)$

NHS direct costs. Both mean

total costs per patient ( $p=0.058)$ and mean

total annual costs per patient ( $p=0.005$ ) higher in

control group $€ 19665 \pm 5256$ versus $€ 8907 \pm 6553$ for the first, and $€ 44134 \pm 11316$ versus $€ 8186 \pm 6553$ for the latter

Indirect costs, differences in loss of earnings not significant

Tele-monitoring of NIV in ALS cost-effective, $€ 700$ per patient per year estimated long-term annual NHS cost saving
Comparison of home on-demand mechanical cough assistance versus institutionalisation and versus continuous access to mechanical in-exsufflation in ALS patients

Cost-effectiveness

2006-2008 39 ALS patients underwent follow-up: NIV $\mathrm{n}=15$, tracheostomy $M V \mathrm{n}=12$, and no ventilation

Mortality, call numbers, respiratory therapist visits, mechanical in-exsufflation requirement, avoided hospitalisations

On-call telephone access costs; respiratory therapist home visits; suction machine rental costs

On-demand in-exsufflator comparison with continuous use of ventilator resulted in

$€ 108758$ cost savings, plus 34 hospitalisations avoided

Telephone access and as needed HMV including manual assisted coughing cost effective
Tele-assistance programme versus usual out-patient follow up in patients with LTOT or HMV

Cost-effectiveness

Prospective randomised clinical trial in $240 \mathrm{CRF}$ patients

Hospitalisations, home exacerbations, ER admissions, urgent GP calls, costeffectiveness

Costs estimated by Medicare DRG

Tele-medicine costs: call centre, nurse and medical second opinions, pulse oximetry device

Healthcare system costs: hospitalisations in respiratory ward and in ICUs, ER admissions, outpatient visits, urgent GP visits, drugs and transportations

Reduction of hospitalisations, higher probability of remaining free of acute exacerbations, higher probability of avoiding GP urgent calls after the first, and higher probability to avoid further ER admissions in tele-assistance group compared with control group

Healthcare costs: deducting telemedicine cost, for tele-assistance patient group the mean overall costs per patient was $€ 8907 \pm 17580$ and $€ 14728 \pm 28694$ for control group

$\mathrm{Au}$ in severe and frail CRF patients on LTOT and or HMV, a nurse-centred tele-assistance programme is effective and cost-effective

NIV: noninvasive ventilation; ALS: amyotrophic lateral sclerosis; LTOT: long-term oxygen therapy; HMV: home mechanical ventilation; MV: mechanical ventilation; CRF: chronic respiratory failure; DRG: diagnosis related group; ER: emergency room; GP: general practitioner; NHS: National Health Service; ICU: intensive care unit. 
applications, devices) is rapidly growing. The convergence between wireless communication technologies and healthcare devices and between health and social care is creating new businesses [4].

\section{Tele-rehabilitation to support VDIs}

As a whole there is a lack of research on the effectiveness of tele-rehabilitation in VDIs. Mandatory items for rehabilitation in VDIs are: education, change in lifestyle, physical activity, muscle training, airway clearance, nutrition [73]. Tele-rehabilitation can be defined as the provision of services to support functional status using technologies [74] according to four models of service delivery: 1) "face to face" standard model used for interactive video conferencing; 2) "tele-homecare" with a nurse coordinating a service named "tele-support"; 3) tele-monitoring with possible interactive tele-evaluation; and 4) tele-care where the patient "plays" or performs exercises under home tele-monitoring and therapist may remotely change settings.

Tele-rehabilitation was promoted through phone calls, and messages, email, video phones, websites or mobile phones, video-conferencing; biological electronic sensors able to send data; medical devices able to be programmed at distance; dedicated Internet software. Timing of application occurred after an hospital discharge or to maintain benefits such as functional independence, education, participation, physical change, early detection of relapses, adherence, airway clearance, exercise training. Among different technologies, video-conferencing can vastly increase the provision of patients (particularly those in rural/ remote areas) with previously difficult access to services [75, 76]. An on-demand tele-consult and mechanical insuflator-exsuflator device access programme avoided hospitalisations due to severe airway encumbrance for patients with ALS with significant cost savings [69].

Age, education, experience in technology, home environment, cognitive deficits, motor and visual ability, phonation and speech play an important role in the patient's ability to use technology during tele-rehabilitation [77]. The training to the use of technology and the structure of the programme should be directed to caregivers in order to make them able to act in accordance with predefined protocols [78]. Whether these positive experiences mostly coming from non VDIs patients can be widely extended to those patients must be confirmed by future research.

\section{Role of tele-monitoring in sleep-related breathing disorders}

Sleep-related breathing disorders are characterised by abnormalities of the respiratory pattern during sleep. The most important are OSA and hypoventilation syndromes, central or ventilatory pump disorders or obesity hypoventilation. CPAP and NIV may benefit these patients [81-81]. With the aim of improving compliance as well as finding new diagnostic strategies, some studies investigated the role of tele-monitoring in the management sleep disorders [81-86].

Although CPAP and NIV may reverse events and can improve survival and quality of life in hypoventilation and nocturnal desaturation in NMD, and in patients with hypoventilation syndromes [79, 87], abnormalities may occur at night, such as air leaks, ventilator-patient asynchrony, central events, and glottic closure leading to desaturations, arousals, impaired sleep architecture, and poor adherence. Polysomnography using conventionally available parameters is an important tool for accurately establishing the device setting avoiding these abnormalities.

Unlike the well-established titration procedure of CPAP in OSA, the approach to follow-up patients with hypoventilation syndromes under NIV is still unclear [88, 89]. In addition, nocturnal monitoring is complex and unforeseen problems arise for many reasons, such as: 1) physiological variations of different variables, 2) clinical problems (pain and secretions, among others) or 3) sleep disturbances. Finally, almost all ventilator types are different, and knowing the algorithms operating in most of them is impossible, which may generate difficulties or even mistakes. Marked differences can occur in ventilator performance, mode of triggering, pressurisation slope and type of exhalation. In addition, leaks and upper airway resistance variations may modify these patterns [88, 89].

According to the American Academy of Sleep Medicine recommendations, titration based on polysomnography using conventionally available parameters is an important tool for accurately establishing devices settings, to avoid abnormalities in most of the patients and to achieve optimal treatment and maximal clinical improvement [90]. The potential of tele-monitoring in hypoventilation syndrome has been less studied and no clear recommendations exist in clinical protocols [39, 87, 91-96] or procedures $[91,97]$. Indeed, ICT seems to have a great potential in this field. For example, in many cases one night and follow-up visits in the sleep laboratory are not enough to adequately set the ventilator, ICT can support the home refinement of the titration of these patients [98]. Tele-consultations can also positively contribute to OSA management [99]. A recent multicentre randomised controlled trial provided evidence that a strategy based on a web platform and tele-consultations, for the CPAP follow-up of OSA 
patients is as effective as the face-to-face approach at lower costs [87]. Caution is needed because data transmitted by commercial devices come from different manufacturer strategies. Standardisation and homogenisation of these data collection and transmission should be regulated by the relevant scientific societies involved [100].

Despite these encouraging results, the penetration of these technological advances in the clinical practice is still slow, especially when compared with other respiratory chronic diseases or others pathologies [98, 99, 101-103]. Furthermore recently published results questioned the validity of this technology as a method to delivery healthcare for all populations [104]. Consequently, it appears crucial to carefully select proper outcomes and most receptive target patients' groups. We believe that it should be critical to assess the role of ICTs in potentially suitable populations, such as patients on CPAP or NIV. At present, two major topics concerning the hypoventilation and sleep should be considered: 1) Clinical procedures: indication of treatment, device titration, and quality control [105], follow-up strategies as well as new approaches to obtain daytime and night-time adequate ventilation and finally treatment compliance. 2) The required innovation: cost-effectiveness analysis, improvement in procedures as well as in technology, specifically by implementing and validating tele-monitoring applications. 3) We lack RCT evaluating the real impact of tele-monitoring on survival in these patients.

\section{Tele-monitoring in palliative care and at the end of life}

Tele-hospice, the use of technologies to provide palliative services to patients with severe chronic disease or living with and dying from advanced illness, may offer an innovative solution to the challenges of providing high-quality, cost-effective end-of-life care. Specifically, the technology used for tele-hospice was video contacts and videophones [32, 106-108] resulting to be both feasible and satisfactory. Most studies were not conducted in VDIs. A 24-h telephone consultation service was proposed to fulfil GPs need dealing with daily dilemmas in palliative care treatment for cancer patients [119]. Tele-hospice interventions may be more readily accepted by nursing and administrative staff members, while those employees who address primarily psychosocial issues may be reluctant to use such technology [110]. Using tele-medicine, it is possible to reduce the number of in-person visits, thereby significantly decreasing the cost of providing hospice care [111]. The use of videophone technology gave providers, patients, and family members' new means to communicate [106]. However, it has been emphasised that it must be considered as an additional tool and not a substitute for actual visits [112]. Patients are usually satisfied with tele-hospice and often express frustration that nurses do not use those pieces of equipment more frequently [113]. Tele-hospice was able to decrease spiritual and medical burden, improving quality of life and symptom management for veterans and families coping with end of life [114]. Home tele-health consultations are a feasible and acceptable means of facilitating a palliative care consultation reducing the burden on families also in paediatric patients $[115,116]$.

We identified only a feasibility study [117], showing the impact in severe CRF patients (13 on HMV) discharged home at the end of their life. The programme consisted of scheduled phone calls, $\mathrm{S}_{\mathrm{PO}_{2}}$ recording, $24 \mathrm{~h}$ call centre, and specialised nurse and physician second opinion. This nurse-centred programme improved communication between hospital staff and the patients' relatives, optimised pain and respiratory symptoms management, improved healthcare assistance and the healthcare needs [117].

\section{Conclusion: problems and future directions}

Due to paucity of literature the style of this document is very anecdotal and it could not provide a systematic analysis of the core problems of tele-monitoring. Nevertheless some conclusions can be made.

1) Variable models of care exist for VDIs [118].

2) Despite the hopes in tele-monitoring as a means to face these problems, much more research is needed before considering tele-monitoring a real improvement in the management of these patients.

3) Tele-monitoring might be a key element in HMV but it is difficult to assess without considering other services received by patients (homecare, access to hospital, social care). Considering the overall care received by the patient, tele-monitoring should be included in the full potential set of "care package" [7].

Major barriers hamper the wider diffusion of tele-monitoring. Solutions of these barriers are areas to be solved for the future [4].

1) Lack of awareness of, and confidence in e-Health solutions among patients, citizens and healthcare professionals.

2) Lack of interoperability between e-Health solutions.

3) Limited large-scale evidence of the cost-effectiveness.

4) Lack of legal clarity.

5) Lack of transparency of utilisation of data collected by such applications. 
6) Inadequate or fragmented legal frameworks including the lack of reimbursement schemes.

7) High start-up costs involved in setting up.

8) Regional differences in accessing ICT services, limited access in deprived areas.

Areas of future research may be effects of tele-monitoring on.

1) Physiological mechanism involved in HMV.

2) Outcomes (survival, quality of life, daily living activities, social interaction, autonomy, self-management, care-giver burden).

3) Health services (phone calls, technical home visits).

4) Resources use (emergency visits, admissions, out-patient visits).

\section{Acknowledgements}

The European Respiratory Society Task Force on Tele-Monitoring of Ventilator-Dependent Patients consisted of: Nicolino Ambrosino and Michele Vitacca (the coordinators); Felip Burgos, Michael Dreher, Joan Escarrabill (Hospital Clinic de Barcelona, Institut d'Investigacions Biomèdiques August Pi i Sunyer (IDIBAPS), Universitat de Barcelona, Barcelona, Spain), Brigitte Fauroux (Pediatric Noninvasive Ventilation and Sleep Unit, AP-HP, Hôpital Necker EnfantsMalades, Paris, France), Miguel Goncalves (Lung Function and Ventilation Unit, Pulmonology Dept, University Hospital of São João, Faculty of Medicine, Porto, Portugal), Valentina Isetta, Michael Kampelmacher, Stefano Mazzoleni (The BioRobotics Institute, Scuola Superiore Sant'Anna, Pisa, Italy; and Rehabilitation Bioengineering Laboratory, Volterra, Italy), Bengt Midgren (Dept of Medical Sciences, Respiratory, Allergy and Sleep Research, Uppsala University, Uppsala, Sweden), Susana Pinto (Instituto de Fisiologia, Instituto de Medicina Molecular, Faculdade de Medicina, Universidade de Lisboa, Lisbon, Portugal), Anita Simonds (NIHR Respiratory and Cardiology Biomedical Research Units, Royal Brompton \& Harefield NHS Foundation Trust, London, UK), Giuseppe Turchetti, Guido Vagheggini, Joao Carlos Winck (members).

\section{References}

1 Lloyd-Owen SJ, Donaldson GC, Ambrosino N, et al. Patterns of home mechanical ventilation use in Europe: results from the Eurovent survey. Eur Respir J 2005; 25: 1025-1031.

2 King AC. Long-term home mechanical ventilation in the United States. Respir Care 2012; 57: 921-930.

3 Farre R, Lloyd-Owen SJ, Ambrosino N, et al. Quality control of equipment in home mechanical ventilation: a European survey. Eur Respir J 2005; 26: 86-94.

4 European Commission. Communication from the commission to the European Parliament, the Council, the European Economic and Social Committee and the Committee of the Regions. eHealth Action Plan 2012-2020 Innovative Healthcare for the 21st century. Brussels, European Commission, 2012. Available from: http://ec. europa.eu/health/ehealth/docs/com_2012_736_en.pdf

5 Evers G, Loey CV. Monitoring patient/ventilator interactions: Manufacturer's perspective. Open Respir Med J 2009; 3: 17-26.

6 Lopes de Almeida JP, Pinto A, Pinto S, et al. Economic cost of home-telemonitoring care for BiPAP-assisted ALS individuals. Amyotroph Lateral Scler 2012; 13: 533-537.

$7 \quad$ Wise MP, Hart N, Davidson C, et al. Home mechanical ventilation. BMJ 2011; 342: d1687.

8 Bashur RL, Shannon GW, Smith BR, et al. The empirical foundations of telemedicine interventions for chronic disease management. Telemed J E Health 2014; 20: 769-800.

9 Pinto A, Almeida JP, Pinto S, et al. Home telemonitoring of non-invasive ventilation decreases healthcare utilisation in a prospective controlled trial of patients with amyotrophic lateral sclerosis. J Neurol Neurosurg Psychiatry 2010; 81: 1238-1242.

10 De Almeida JP, Pinto AC, Pereira J, et al. Implementation of a wireless device for real-time telemedical assistance of home-ventilated amyotrophic lateral sclerosis patients: a feasibility study. Telemed J E Health 2010; 16: 883-888.

11 Zamarrón C, Morete E, González F. Telemedicine system for the care of patients with neuromuscular disease and chronic respiratory failure. Arch Med Sci 2014; 10: 1047-1051.

12 Garuti G, Bagatti S, Verucchi E, et al. Pulmonary rehabilitation at home guided by telemonitoring and access to healthcare facilities for respiratory complications in patients with neuromuscular disease. Eur J Phys Rehabil Med 2013; 49: 51-57.

13 Köhnlein T, Windisch W, Köhler D, et al. Non-invasive positive pressure ventilation for the treatment of severe stable chronic obstructive pulmonary disease: a prospective, multicentre, randomised, controlled clinical trial. Lancet Respir Med 2014; 2: 698-705.

14 Vitacca M, Assoni G, Pizzocaro P, et al. A pilot study of nurse-led, home monitoring for patients with chronic respiratory failure and with mechanical ventilation assistance. J Telemed Telecare 2006; 12: 337-342.

15 Borel JC, Pelletier J, Taleux N, et al. Parameters recorded by software of non-invasive ventilators predict COPD exacerbation: a proof-of-concept study. Thorax 2015; 70: 284-285.

16 Pallero M, Puy C, Güell R, et al. Ambulatory adaptation to noninvasive ventilation in restrictive pulmonary disease: a randomized trial with cost assessment. Respir Med 2014; 108: 1014-1022.

17 Hazenberg A, Kerstjens HA, Prins SC, et al. Initiation of home mechanical ventilation at home: a randomised controlled trial of efficacy, feasibility and costs. Respir Med 2014; 108: 1387-1395.

18 Vitacca M, Guerra A, Assoni G, et al. Weaning from mechanical ventilation followed at home with the aid of a telemedicine program. Telemed J E Health 2007; 13: 445-449.

19 Bashshur R, Shannon G, Krupinski E, et al. The taxonomy of telemedicine. Telemed J E Health 2011; 17: 484-494.

20 Dolin RH, Alschuler L, Boyer S, et al. HL7 Clinical document architecture, release 2. J Am Med Inform Assoc 2006; 13: 30-39. 
Cano I, Alonso A, Hernandez C, et al. An adaptive case management system to support integrated care services: Lessons learned from the NEXES project. J Biomed Inform 2015; 55: 11-22.

Bertini S, Picariello M, Gorini M, et al. Telemonitoring in chronic ventilatory failure: a new model of surveillance, a pilot study. Monaldi Arch Chest Dis 2012; 77: 57-66.

Vitacca M, Bianchi L, Guerra A, et al. Tele-assistance in chronic respiratory failure patients: a randomised clinical trial. Eur Respir J 2009; 33: 411-418.

Ritchie C, Richman J, Sobko H, et al. The E-coach transition support computer telephony implementation study: protocol of a randomized trial. Contemp Clin Trials 2012; 33: 1172-1179.

Miyasaka K, Suzuki Y, Sakai H, et al. Interactive communication in high-technology home care: videophones for pediatric ventilatory care. Pediatrics 1997; 99: E1.

Vontetsianos T, Giovas P, Katsaras T, et al. Telemedicine-assisted home support for patients with advanced chronic obstructive pulmonary disease: preliminary results after nine-month follow-up. J Telemed Telecare 2005; 11: Suppl. 1, 86-88.

Holland AE, Hill CJ, Rochford P, et al. Telerehabilitation for people with chronic obstructive pulmonary disease: feasibility of a simple, real time model of supervised exercise training. J Telemed Telecare 2013; 19: 222-226.

Smith CE, Cha JJ, Kleinbeck SV, et al. Feasibility of in-home telehealth for conducting nursing research. Clin Nurs Res 2002; 11: 220-233.

Paget T, Jones C, Davies M, et al. Using home telehealth to empower patients to monitor and manage long term conditions. Nurs Times 2010; 106: 17-19.

Takahashi PY, Hanson GJ, Thorsteinsdottir B, et al. The impact of telemonitoring upon hospice referral in the community: a randomized controlled trial. Clin Interv Aging 2012; 7: 445-451.

Segrelles Calvo G, Gómez-Suárez C, Soriano JB, et al. A home telehealth program for patients with severe COPD: the PROMETE study. Respir Med 2014; 108: 453-462.

Ure J, Pinnock H, Hanley J, et al. Piloting tele-monitoring in COPD: a mixed methods exploration of issues in design and implementation. Prim Care Respir J 2012; 21: 57-64.

Pinnock H, Hanley J, McCloughan L, et al. Effectiveness of telemonitoring integrated into existing clinica services on hospital admission for exacerbation of chronic obstructive pulmonary disease: researcher blind, multicentre, randomised controlled trial. BMJ 2013; 347: f6070.

Zamith M, Cardoso T, Matias I, et al. Home telemonitoring of severe chronic respiratory insufficient and asthmatic patients. Rev Port Pneumol 2009; 15: 385-417.

Trappenburg JC, Niesink A, de Weert-van Oene GH, et al. Effects of telemonitoring in patients with chronic obstructive pulmonary disease. Telemed J E Health 2008; 14: 138-146.

Alonso A. A new model for home care for COPD. Stud Health Technol Inform 2004; 103: 368-373.

Pedone C, Chiurco D, Scarlata S, et al. Efficacy of multiparametric telemonitoring on respiratory outcomes in elderly people with COPD: a randomized controlled trial. BMC Health Serv Res 2013; 13: 82.

Antoniades NC, Rochford PD, Pretto JJ, et al. Pilot study of remote telemonitoring in COPD. Telemed J E Health 2012; 18: 634-640.

Fraysse JL, Delavillemarque N, Gasparutto B, et al. La télé-observance à domicile de la pression positive continue: étude de faisabilité [Home telemonitoring of CPAP: a feasibility study]. Rev Mal Respir 2012; 29: 60-63.

Ishida R, Yonezawa $\mathrm{Y}$, Maki $\mathrm{H}$, et al. A wearable, mobile phone-based respiration monitoring system for sleep apnea syndrome detection. Biomed Sci Instrum 2005; 41: 289-293.

Nikander K, Denyer J, Dodd M, et al. The Adaptive Aerosol Delivery system in a telehealth setting: patient acceptance, performance and feasibility. J Aerosol Med Pulm Drug Deliv 2010; 23: Suppl. 1, S21-S27.

Maiolo C, Mohamed EI, Fiorani CM, et al. Home telemonitoring for patients with severe respiratory illnesses: the Italian experience. J Telemed Telecare 2003; 9: 67-71.

Casas A, Troosters T, Garcia-Aymerich J, et al. Integrated care prevents hospitalizations for exacerbations in COPD patients. Eur Respir J 2006; 28: 123-130.

Fox N, Hirsch-Allen AJ, Goodfellow E, et al. The impact of a telemedicine monitoring system on positive airway pressure adherence in patients with obstructive sleep apnea: a randomized controlled trial. Sleep 2012; 35: 477-481.

Moreira J, Freitas C, Redondo M, et al. Compliance with home non-invasive mechanical ventilation in patients with chronic respiratory failure: Telemonitoring versus usual care surveillance-a randomized pilot study. Eur Respir J 2014; 44: Suppl. 58, 447.

Vitacca M, Comini L, Assoni G, et al. Tele-assistance in patients with amyotrophic lateral sclerosis: long term activity and costs. Disabil Rehabil Assist Technol 2012; 7: 494-500.

Vitacca M, Comini L, Tentorio M, et al. A pilot trial of telemedicine-assisted, integrated care for patients with advanced amyotrophic lateral sclerosis and their caregivers. J Telemed Telecare 2010; 16: 83-88.

Vitacca M, Bazza A, Bianchi L, et al. Tele-assistance in chronic respiratory failure: patients' characterization and staff workload of 5-year activity. Telemed J E Health 2010; 16: 299-305.

de Toledo P, Jiménez S, del Pozo F, et al. Telemedicine experience for chronic care in COPD. IEEE Trans Inf Technol Biomed 2006; 10: 567-573.

Jódar-Sánchez F, Ortega F, Parra C, et al. Implementation of a telehealth programme for patients with severe chronic obstructive pulmonary disease treated with long-term oxygen therapy. J Telemed Telecare 2013; 19: 11-17. Bauer KA. The ethical and social dimensions of home-based telemedicine. Crit Rev Biomed Eng 2000; 28: 541-544. Stanberry B. Legal and ethical aspects of telemedicine. J Telemed Telecare 2006; 12: 166-175.

Brahams D. The medico-legal implications of teleconsulting in the UK. J Telemed Telecare 1995; 1: 196-201.

Greene J, Yellowlees PM. Electronic and remote prescribing: administrative, regulatory, technical, and clinical standards and guidelines, April 2013. Telemed J E Health 2014; 20: 63-74.

American College of Physicians. E-Health and Its Impact on Medical Practice. Philadelphia American College of Physicians. Philadelphia, American College of Physicians, 2008. Available from: https://www.acponline.org/acp_ policy/policies/ehealth_impact_medical_practices_2008.pdf

Kaufman DR, Patel VL, Hilliman C, et al. Usability in the real world: assessing medical information technologies in patients' homes. J Biomed Inform 2003; 36: 45-60.

European Commission. Commission Staff Working Document on the Applicability of the Existing EU Legal Framework to Telemedicine Services. Accompanying the Document: Communication from the commission to 
the European Parliament, the Council, the European Economic and Social Committee and the Committee of the Regions eHealth Action Plan 2012-2020 - Innovative Healthcare for the 21st Century 2012. Brussels, European Commission, 2012. Available from: http://ec.europa.eu/economy_finance/publications/european_economy/2012/ pdf/ee-2012-2_en.pdf

58 European Commission. Health care expenditure. In: 2012 Ageing Report: Economic and Budgetary Projections for the 27 EU Member States (2010-2060). Brussels, European Commission, 2012; pp. 157-194. Available from: http://ec.europa.eu/economy_finance/publications/european_economy/2012/pdf/ee-2012-2_en.pdf

59 European Commission. Long-term care. In: 2012 Ageing Report: Economic and Budgetary Projections for the 27 EU Member States (2010-2060). Brussels, European Commission, 2012; pp. 195-246. Available from: http://ec. europa.eu/economy_finance/publications/european_economy/2012/pdf/ee-2012-2_en.pdf

60 Garuti G, Lusuardi M. Respiratory home care: take the pulmonary specialist out of the hospital! Monaldi Arch Chest Dis 2009; 71: 93-95.

61 Geiseler J, Karg O, Börger S, et al. Invasive home mechanical ventilation, mainly focused on neuromuscular disorders. GSM Health Technol Assess 2010; 6: Doc 08.

62 Commission of the European Communities. Green Paper on the European Workforce for Health COM. Brussels, European Commission, 2008. Available from: http://ec.europa.eu/health/ph_systems/docs/workforce_gp_en.pdf

63 Doherty ST, Oh P. A multi-sensor monitoring system of human physiology and daily activities. Telemed J E Health 2012; 18: 185-192.

64 Nield M, Hoo GW. Real-time telehealth for COPD self-management using Skype ${ }^{\mathrm{TM}}$. COPD 2012; 9: 611-609.

65 Sevick MA, Sereika S, Hoffman LA, et al. A confirmatory factor analysis of the Caregiving Appraisal Scale for caregivers of home-based ventilator-assisted individuals. Heart Lung 1997; 26: 430-438.

66 Fields A, Rosenblatt A, Pollak M, et al. Home care cost-effectiveness for respiratory technology-dependent children. Am J Dis Child 1991; 145: 729-233.

67 Balinsky W. Pediatric home care: reimbursement and cost benefit analysis. J Pediatr Health Care 1999; 13: 288-294.

68 Noyes J, Godfrey C, Beecham J. Resource use and service costs for ventilator-dependent children and young people in the UK. Health Soc Care Commun 2006; 14: 508-522.

69 Vitacca M, Paneroni M, Trainini D, et al. At home and on demand mechanical cough assistance program for patients with amyotrophic lateral sclerosis. Am J Phys Med Rehabil 2010; 89: 401-406.

70 Cartwright M, Hirani SP, Rixon L, et al. Effect of telehealth on quality of life and psychological outcomes over 12 months (Whole Systems Demonstrator telehealth questionnaire study): nested study of patient reported outcomes in a pragmatic, cluster randomised controlled trial. BMJ 2013; 346: f653.

71 Henderson C, Knapp M, Fernández JL, et al. Cost effectiveness of telehealth for patients with long term conditions (Whole Systems Demonstrator telehealth questionnaire study): nested economic evaluation in a pragmatic, cluster randomised controlled trial. BMJ 2013; 346: f1035.

72 Stoddart A, van der Pol M, Pinnock H, et al. Telemonitoring for chronic obstructive pulmonary disease: a cost and cost-utility analysis of a randomised controlled trial. J Telemed Telecare 2015; 21: 108-118.

73 Ambrosino N, Clini E. Response to pulmonary rehabilitation: toward personalized programs? Eur Respir J 2015; 46: $1538-1540$.

74 Winters JM. Telerehabilitation research: emerging opportunities. Ann Rev Biomed Eng 2002; 2: 287-320.

75 Jarvis-Selinger S, Chan E, Payne R, et al. Clinical telehealth across the disciplines: lessons learned. Telemed J E Health 2008; 14: 720-725.

76 Swash M. Internet facilitated management improves home ventilation in amyotrophic lateral sclerosis. $J$ Neurol Neurosurg Psychiatry 2010; 81: 1180 .

77 Lathan CE, Kinsella A, Rosen MJ, et al. Aspects of human factors engineering in home telemedicine and telerehabilitation systems. Telemed J 1999; 5: 169-175.

78 Brennan DM, Lindey MB. Human factors in the development and implementation of telerehabilitation systems. J Telemed Telecare 2008; 14: 55-58.

79 Aboussouan LS. Sleep-disordered breathing in neuromuscular Disease. Am J Respir Crit Care Med 2015; 191: 979-989.

80 Piper A. Obesity hypoventilation syndrome: weighing in on therapy options. Chest 2016; 149: 856-868.

81 Wozniak DR, Lasserson TJ, Smith I. Educational, supportive and behavioural interventions to improve usage of continuous positive airway pressure machines in adults with obstructive sleep apnoea. Cochrane Database Syst Rev 2014; 1: CD007736.

82 Bruyneel M, Ninane V. Unattended home-based polysomnography for sleep disordered breathing: Current concepts and perspectives. Sleep Med Rev 2014; 18: 341-347.

83 Coma-Del-Corral MJ, Alonso-Álvarez ML, Allende M, et al. Reliability of telemedicine in the diagnosis and treatment of sleep apnea syndrome. Telemed J E Health 2013; 19: 7-12.

84 Isetta $\mathrm{V}$, León $\mathrm{C}$, Torres $\mathrm{M}$, et al. Telemedicine-based approach for obstructive sleep apnea management: building evidence. Interact J Med Res 2014; 3: e6.

85 Dellacà R, Montserrat JM, Govoni L, et al. Telemetric CPAP titration at home in patients with sleep apnea-hypopnea syndrome. Sleep Med 2011; 12: 153-157.

86 Isetta V, Negrín MA, Monasterio C, et al. A Bayesian cost-effectiveness analysis of a telemedicine-based strategy for the management of sleep apnoea: a multicentre randomised controlled trial. Thorax 2015; 70: 1054-1061. Simonds AK. Chronic hypoventilation and its management. Eur Respir Rev 2013; 22: 325-332.

88 Rabec C, Rodenstein D, Leger P, et al. Ventilator modes and settings during non-invasive ventilation: effects on respiratory events and implications for their identification. Thorax 2011; 66: 170-178.

89 Gonzalez-Bermejo J, Perrin C, Janssens JP, et al. Proposal for a systematic analysis of polygraphy or polysomnography for identifying and scoring abnormal events occurring during non-invasive ventilation. Thorax 2012; 67: 546-552.

90 Berry RB, Budhiraja R, Gottlieb DJ, et al. Rules for scoring respiratory events in sleep: update of the 2007 AASM manual for the scoring of sleep and associated events. Deliberations of the Sleep Apnea Definitions Task Force of the American Academy of Sleep Medicine. J Clin Sleep Med 2012; 8: 597-619.

91 Mokhlesi B, Tulaimat A. Recent advances in obesity hypoventilation syndrome. Chest 2007; 132: 1322-1336. 

Med 2013; 187: 1046-1055.

93 Hess DR. The growing role of noninvasive ventilation in patients requiring prolonged mechanical ventilation. Respir Care 2012; 57: 900-918.

94 Piper AJ. Nocturnal hypoventilation - identifying \& treating syndromes. Indian J Med Res 2010; 131: $350-365$.

95 Piper AJ, Grunstein RR. Obesity hypoventilation syndrome: mechanisms and management. Am J Respir Crit Care Med 2011; 183: 292-298.

96 Piper AJ, Grunstein RR. Big breathing: the complex interaction of obesity, hypoventilation, weight loss, and respiratory function. J Appl Physiol 2010; 108: 199-205.

97 Vitacca M, Escarrabill J, Galavotti G, et al. Home mechanical ventilation patients: a retrospective survey to identify level of burden in real life. Monaldi Arch Chest Dis 2007; 67: 142-147.

98 Kitsiou S, Paré G, Jaana M. Systematic reviews and meta-analyses of home telemonitoring interventions for patients with chronic diseases: a critical assessment of their methodological quality. J Med Internet Res 2013; 15: e150. McLean S, Nurmatov U, Liu JL, et al. Telehealthcare for chronic obstructive pulmonary disease: Cochrane Review and meta-analysis. Br J Gen Pract 2012; 62: e739-e749.

100 Luján M, Pomares X. Ventilación mecánica no invasiva. Reflections on Home Monitoring. Arch Bronconeumol 2014; 50: $85-86$.

101 Wootton R. Twenty years of telemedicine in chronic disease management-an evidence synthesis. $J$ Telemed Telecare 2012; 18: 211-220.

102 Xiang R, Li L, Liu SX. Meta-analysis and meta-regression of telehealth programmes for patients with chronic heart failure. J Telemed Telecare 2013; 19: 249-259.

103 Palaniswamy C, Mishkin A, Aronow WS, et al. Remote patient monitoring in chronic heart failure. Cardiol Rev 2013; 21: 141-150.

104 Hall WJ. ACP Journal Club. Telemonitoring did not reduce hospitalizations or ED visits in high-risk elderly patients. Ann Intern Med 2012; 157: JC3-JC8.

105 Farré R, Navajas D, Prats E, et al. Performance of mechanical ventilators at the patient's home: a multicentre quality control study. Thorax 2006; 61: 400-404.

106 Whitten P, Doolittle G, Mackert M. Telehospice in Michigan: use and patient acceptance. Am J Hosp Palliat Care 2004; 21: 191-195.

107 Chen CY, Thorsteinsdottir B, Cha SS, et al. Health care outcomes and advance care planning in older adults who receive home-based palliative care: a pilot cohort study. J Palliat Med 2015; 18: 38-44.

108 Laila M, Rialle V, Nicolas L, et al. Videophones for the delivery of home healthcare in oncology. Stud Health Technol Inform 2008; 136: 39-44.

109 Teunissen SC, Verhagen EH, Brink M, et al. Telephone consultation in palliative care for cancer patients: 5 years of experience in The Netherlands. Support Care Cancer 2007; 15: 577-582.

110 Johnston B. UK telehealth initiatives in palliative care: a review. Int J Palliat Nurs 2011; 17: 301-308.

111 Washington KT, Demiris G, Oliver DP, et al. Telehospice acceptance among providers: a multidisciplinary comparison. Am J Hosp Palliat Care 2008; 25: 452-457.

112 Doolittle GC, Whitten P, McCartney M, et al. An empirical chart analysis of the suitability of telemedicine for hospice visits. Telemed J E Health 2005; 11: 90-97.

113 Demiris G, Oliver DR, Fleming DA, et al. Hospice staff attitudes towards telehospice. Am J Hosp Palliat Care 2004; 21: 343-347.

114 Maudlin J, Keene J, Kobb R. A road map for the last journey: home telehealth for holistic end-of-life care. Am J Hosp Palliat Care 2006; 23: 399-403.

115 Bradford NK, Young J, Armfield NR, et al. Home telehealth and paediatric palliative care: clinician perceptions of what is stopping us? BMC Palliat Care 2014; 13: 29.

116 Wilkinson OM, Duncan-Skingle F, Pryor JA, et al. A feasibility study of home telemedicine for patients with cystic fibrosis awaiting transplantation. J Telemed Telecare 2008; 14: 182-185.

117 Vitacca M, Assoni G, Gilè S, et al. Telemedicine to support end of life in severe chronic respiratory failure patients at home. J Med Pers 2009; 7: 85-90.

118 Rose L, McKim D, Katz S, et al. Institutional care for long-term mechanical ventilation in Canada: a national survey. Can Respir J 2014; 21: 357-362. 